\title{
SOBRE EL SUJETO: ¿̨DELEUZE VERSUS BADIOU?
}

\author{
Cristina MARQUÉs Rodilia \\ Doctora en Filosofía DEA en Psicoanálisis, París-VIII
}

\begin{abstract}
RESUMEN: En el marco de la filosofía francesa reciente el único colega al que Badiou podía considerar como «semejante», es decir, clásico, con su inevitable intersección de admiración y rechazo, era el ontólogo Deleuze cuyo clamor del ser dio lugar a una correspondencia, que nunca conoció el trato personal y que Deleuze cortó. Este corte en la discusión teórica parece poner de manifiesto la imposibilidad de acercamiento de sus respectivas posiciones. Voy a atreverme a especular sobre algunas de las divergencias que les impedían sostener un discurso común.
\end{abstract}

\section{Introducción}

A pesar de que Deleuze es un filósofo aristocrático, hay una faceta pública que le muestra como el filósofo de los deseos anárquicos de las máquinas que pueblan la Tierra con sus producciones. Un filósofo de sensibilidad postmoderna, más próximo a Foucault que a la metafísica de la representación, furibundo antiplatónico, aliado de la lógica del sentido más que defensor de la verdad; sin embargo este personaje ligado al mayo del 68 escribió: «Es justamente del autómata así purificado que se adueña el pensamiento del afuera, como lo impensable en el pensamiento" ". Aquí está, en "lo impensable en el pensamiento" una de las divergencias fundamentales con Badiou.

1 Deleuze, G.: Cinéma 2: l'image-temps, Paris, Minuit, 1985, (La imagen-tiempo.Estudios sobre cine 2, Barcelona, Paidos,.1987, p. 233. 
El escollo que primero salta a la vista, es la diferencia que Badiou establece entre ontología y filosofía, en tanto que Deleuze las identifica. El hecho de que el Ser sea Uno y sólo Uno, aunque pueda tomar, a lo largo del espacio y del tiempo, las más variadas y nómadas apariencias, no es admisible para Badiou que defiende un pensamiento ontológico de corte platónico.

El platonismo de Badiou consiste en identificar la Idea con el múltiple puro: no multiplicidad del Uno sino multiplicidad del cero, porque siendo el ser lo mismo que el vacío, no puede ocurrir más que la infinita multiplicación del vacío que genera una multiplicidad sin Uno.

Lo cierto es que para Deleuze, nada hay más allá del suelo de la Vida, cuyo polimorfismo clama y recuerda su expansión superficial en planos de distinta intensidad, que siempre mantienen la univocidad del Ser y, por tanto, su imposible división en categorías. Aquí está el motivo por el que ambos pueden ser calificados de clásicos dentro de la filosofia francesa contemporánea: no se someten a las exigencias críticas de Kant. Se oponen a la caída de la metafísica. En términos deleuzianos podríamos afirmar que ambos se oponen a cualquier "retorno a Kant".

Se exigen pensar el devenir del mundo y su fundamento. Sea éste el univoco Uno o el múltiple de múltiples cuyo único asiento es el vacío, ambos se comprometen firmemente con el pensamiento del Ser. Pero ambos divergen en cuanto al par virtual/actual: Para Deleuze el Uno es un reservorio infinito de producciones divergentes, mientras que Badiou sacrifica el Uno en su búsqueda de una perpetua actualidad de lo múltiple. Intemporal actualidad del vacío versus infinita virtualidad de lo unívoco en su imparable despliegue a distintas velocidades.

Si para Deleuze hay un planteamiento metodológico fundado en la física, para Badiou el método es matemático y, más exactamente, circunscrito a la teoría de conjuntos y al infinito cantoriano. Y aunque los dos son partidarios de las realidades "événementielles», conciben el acontecimiento de manera bien distinta. Tan distinta como la repetición y la novedad. Deleuze contempla el eterno

2 Deleuze, G.: «En todos mis libros he estado buscando la naturaleza del acontecimiento». "Me he pasado el tiempo escribiendo sobre esta noción de acontecimiento". Pourparlers, Paris, Minuit, 1990, (Conversaciones, Valencia, Pretextos, 1995), pp. 194 y 218. 
retorno de lo Mismo como la pura diferencia, mientras que para Badiou sólo el forzamiento de un sujeto militante puede dar fe del acontecimiento como ruptura, como derrota de la repetición propia de cada situación.

Siendo el acontecimiento el eje vertebrador de ambas concepciones del Ser, el sujeto concebido por ambos es tan divergente como su perspectiva respecto a «lo impensable del pensamiento». Para Deleuze el sujeto es un punto ciego, un autómata, mientras que para Badiou es un rastreador cuyo olfato descubre la escondida pieza. En este artículo voy considerar sus concepciones de sujeto.

La noción de sujeto en Badiou está "contaminada" por el psicoanálisis dado que Badiou atraviesa la noción de goce de Lacan para establecer el amor y el deseo como condiciones de posibilidad de la filosofía. Deleuze no está menos influido por el psicoanálisis, y muy especialmente, del psicoanálisis francés encarnado en la figura de Lacan a la que sataniza por su «vuelta a todo Freud». Sin embargo, considero que la influencia del estructuralismo y de Lacan fue decisiva para que Deleuze encarnara un decir clínico, a la par que rechazaba el confesionario lacaniano porque lo consideraba demasiado subjetivo. Para Deleuze era inadmisible hacer del sujeto un vacío donde se instalara la estructura. El sujeto de Deleuze no es más que un pliegue del afuera, un autómata pensante, que cuando "retoma" a Freud, Lacan, etc., se torna reactivo, detenido en su actividad y corrompido.

Si para Badiou el sujeto es sólo un trazo, para Deleuze es algo aún más impersonal, se reduce a una intensidad, la actualización momentánea y parcial del Pensar. El enamorado sujeto de Badiou persigue el acontecimiento indiscernible y lo hace existir con su fidelidad. La fidelidad de pensamiento en Deleuze es saberse impelido por la fuerza que desde el abierto afuera actualiza las síntesis divergentes.

Pero para mejor analizar las diferencias entre el militante de Badiou y los autómatas purificados necesito una mediación. El sujeto del deseo de Lacan me servirá como mediación. Para ambos el deseo es crucial aunque cumpla misiones bien distintas. El deseo es para Badiou, como para Platón, el erotizado instrumento que el amor utiliza para ascender hasta lo amado, mientras que el amor no está en el vocabulario de Deleuze. La filosofía es ontología, entendida como despliegue incesante del Ser que se metamorfosea en infinitos modos, simultáneamente divergentes en apariencia, pero idénticos en el gran circuito. 
El deseo que conduce al amor y éste a la religación, al lazo social, a través de la feminizada filosofía, es algo inaudito para Deleuze, que considera al deseo como la fuerza física que impele al ser en su incansable despliegue-repliegue. No se trata de amar y de convertirse en el fiel testigo del acontecimiento, sino de levantar acta del acontecimiento como mostración de la multiplicidad de simulacros originados por el Ser en su inacabable, y siempre reiterado, despliegue, pliegue, y repliegue. Multiplicidad sí, pero de los infinitos modos de ser de la Vida en su eterno retorno, mientras que para Badiou lo múltiple es el vacío. El vacío es el nombre del Ser porque con las reglas axiomáticas de la teoría de conjuntos el vacío se multiplica, a partir de los axiomas correspondientes, en infinitos infinitos, todos ellos actuales como quería el matemático platónico Cantor.

No obstante, tirando del hilo del deseo nos vemos abocados al del sentido. Entre el ser y el sentido no hay duda, tanto Deleuze como Lacan se inclinan por el ser y el sinsentido, y aunque sus caminos diverjan la omnipotente estructura juega, salvo en el caso de Badiou, un papel determinante. La estructura es incompleta porque tiene una casilla vacía que la pone en movimiento o como dice Deleuze: ${ }^{3}$ llugar muerto, lugar del rey, tarea ciega, significante flotante, valor cero, ángulo muerto, o causa ausente, etc.,», que permiten pensar, así lo hacen Lacan y Deleuze, que la estructura es una máquina de producir sentidos. Lo que no excluye que el sinsentido esté en el origen, o mejor dicho, en la falta de origen. De este modo los hechos de habla del lingüista, los sueños sintomáticos del psicoanálisis y las reglas de parentesco de los antropólogos, se escapan por el punto de fuga de la casilla vacía. La casilla vacía demuestra que la estructura ficciona (fictionne) el sentido, pero que ella queda fuera de esta ficción (fictionné). Por eso Badiou considera nefasto para la filosofía el uso del lenguaje como pura combinatoria, o la reducción de las matemáticas al cálculo, porque no está dispuesto a admitir que la Estructura sea una presencia hecha de ausencia y con un significante sin significado.

Me dispongo pues, a centrarme en el sujeto, noción considerada ad nauseam en la filosofía del pasado siglo XX, y que en Francia desde Descartes para acá ha constituido el epicentro del pensamiento. No resulta vano subrayar las dis-

${ }^{3}$ Deleuze, G.: Logique du sens, Paris, Minuit, 1969. (Lógica del sentido, Barcelona, Paidos, 1989), p. 88. 
tintas posiciones de Deleuze y Badiou respecto a Descartes. Deleuze no tolera la colaboración con "el largo error» que la intuición al estilo cartesiano representa: la intuición inmediata, en un solo golpe de vista, es un "aislamiento", ilegítimo, en nombre de la claridad, del fondo total y oscuro que las produce; aisladas, puntuales, las intuiciones son como móviles inflexiones, del ser unívoco. Igualmente, sus divergentes apreciaciones de la obra de Foucault dan buena cuenta, de la imposible convergencia de sus respectivas nociones de sujeto.

El sujeto deleuziano puro pliegue de la exterioridad, espontáneamente perseguido por el afuera, no es homologable al sujeto militante que fuerza el acontecimiento a la existencia; ambos están urgidos por el afuera, pero esta exterioridad del sujeto es, como veremos, radicalmente distinta. El acontecimiento se da en situación, dice Badiou, corta la repetición y aparece por azar la gracia, el don, de lo nuevo impredecible. El acontecimiento de Deleuze es igualmente impredecible y azaroso, pero es un don que vuelve. Novedad que rompe la repetición, versus eterno retorno. Se hace difícil para Deleuze renunciar a la idea, sostenida por la física clásica o galileismo, de una realidad exterior, mientras que para la visión matemática de Badiou el único afuera es el vacío del ser, que se puede hacer equivalente al conjunto vacío, con el que el tándem Leibniz/Frege aseguran la validez del principio de no-contradicción.

Comenzaremos por el sujeto que Badiou exonera del psicoanálisis aunque tiene que ser gozante y enamorado para poder asumir la dura tarea que le impone ser el guardián del acontecimiento, atento a su epifanía . Describiremos, a continuación, el nómada discurrir del sujeto del acontecimiento deleuziano; sujeto de los múltiples simulacros que la Vida le impone, encadenado como está al eterno retorno de lo Mismo, que no es sino el nombre de la pura diferencia.

Pasaremos, pues, del gesto platónico de Badiou al estoicismo del héroe nietzscheano, pero utilizaremos la mediación del sujeto lacaniano, que construido a expensas de la estructura, hace del lenguaje el amo del juego. Este sujetado sujeto nos introduce tanto en el sujeto sin objeto de Badiou como en el sujeto pliegue en el que incansablemente se despliega el omnipresente y unívoco Ser. 


\section{Sujetos: del deseo, militante y autómata}

\subsection{Sujeto vacío versus vacio del ser}

La diferencia que amenaza con mayor empuje la compatibilidad entre los discursos de Lacan y Badiou reside en la localización del vacío. El vacío es el nombre del ser de Badiou, el vacío del sujeto es donde, según Lacan, la estructura lingüística se coloca.

Y el conflicto no reside tanto en la amplitud del vacío dado que podría concederse que el vacío del que habla Lacan es un vacío regional que en nada entorpecería un vacío generalizado. El conflicto reside en que el vacío de Lacan es un vacío con bordes, un intervalo perfectamente localizado que se dice como el trayecto que va desde un resto corporal a un objeto topológico.

Lacan utilizaba las secundinas para urdir el mito de la laminilla, explicando así, de forma imaginaria, el vacío dejado por das Ding. Si el sujeto sufre una reducción de goce que le impide para siempre la completa satisfacción es porque al separarnos de nosotros mismos, en el parto, perdemos la otra mitad que nos completaría; no es difícil detectar aquí el rastro del mítico personaje platónico. La versión de Lacan promociona el momento biológico de la separación, y el andrógino de Platón, el momento del castigo que ocasiona la pérdida de la otra mitad. Podría afirmarse que la búsqueda del Uno perdido recorre el pensamiento occidental. Uno al que renuncian tanto Lacan como Badiou.

No es el caso de Deleuze que vigorosamente clama la afirmación del Uno, unívoco Ser, señor de la ontología que se metamorfosea en múltiples acontecimientos, nuevos presentes, sucesión de presentes que exige el aumento de dimensiones con diversas intensidades. Juego de espejos de la virtualidad subyacente.

Lacan afirma $Y$ a de l'Un, pero ese uno es el objeto "aa", falo simbólico con que la cura termina si es que ésta llega a su fin. Así, el Uno no es un elemento de la metafísica de la presencia, sino un objeto simbólico producido por el diseño y la técnica psicoanalítica. No se trata del Uno con mayúsculas que concede la dignidad a la humanidad, es un objeto topológico que se ha ido produciendo, tejiéndose con la trama urdida por la libre asociación del analizante y el corte interpretativo del analista. Este uno es el final de un proceso de recuperación y transformación de un resto corporal que es el material de desecho del parto. 
Freud pone más tarde este momento de pérdida que califica de ürverdrängung, lo pone después del destete, en el momento en que la separación de la madre se hace definitiva. Para Lacan, más que separarse de la madre se trata de separarse de uno mismo; separarse de la telilla en la que el feto ha permanecido envuelto durante el periodo de gestación. Lo semejante en ambos casos reside en que es una fábula, un relato imaginario que viene a expresar una pérdida ocurrida en un pasado que nunca fue presente.

Puesto que se trata de hacer una semblanza del objeto perdido que es lo imposible, la diferencia innombrable, hay que producir un objeto simbólico para colocarlo en el hueco real que esa pérdida circunscribe; hay que recurrir a una técnica y a una teoría que sea capaz de expresar con exactitud lo que esa carencia significa: la finitud. La falta en ser es el hueco real dejado por ese objeto que nos descompleta sumiéndonos en la finitud; dejándonos en la insatisfacción pulsional.

Como consecuencia de este descompletamiento de ser, de este recorte de goce, el vacío del sujeto del inconsciente es un vacío perfectamente delimitado, con bordes, y además, lo que adviene, el objeto «a», para suplir la falta original y originaria no es una novedad. El acontecimiento propicio que es la producción y advenimiento del plus-de-goce no puede ser calificado sensu estricto de acontecimiento porque se trata de la llegada de un lugarteniente o representante de la representación perdida y reconstruida verbalmente a lo largo de la cura. El plus-de-goce es una presencia vicaria, un hypokeimenón, en el sentido que ya Aristóteles le da a este término.

El decir clínico que usa Deleuze es para advertirnos de que el vacío como desfundamiento (effondement) es sólo aparente porque la fuerza-tiempo tiene diversas intensidades, parcialidades actuales que impiden ver lo subyacente virtual. Un corte puede llevarnos al fondo caótico que constituye el suelo de la univocidad del Ser. La división categorial es sólo aparente, lo que hay son modos transitorios, presentes sustituidos por otros que le suceden y que llamamos acontecimientos.

El vacío que concibe Badiou no tiene límites, es pura sustracción del exceso abigarrado que constituye el múltiple de nada. El plus-de-goce y el acontecimiento que Badiou acuña son bien distintos. El acontecimiento de Badiou 
requiere el corte en una situación o conjunto de elementos que han sido contados por uno, quedando el sujeto excluido de esa cuenta. En esa situación habrá una localización de elementos que no han sido contados por la situación: el exceso de elementos impresentado por la situación exige el recorte de un subconjunto extraordinario de la situación.

Así, para Badiou no es sólo que el Uno se reduzca a la cuenta o reunificación de una multitud de elementos, sino que entre estos, no está el sujeto; además, el sujeto de Badiou no se encuentra con el rastro de algo perdido por él. En la ontología de la sustracción de Badiou no hay ninguna huella que oriente la búsqueda y fije el objetivo del sujeto.

El acontecimiento de Deleuze es un Instante porque el presente no sirve para explicar que el tiempo pasa. En el intervalo que llamamos presente ocurre algo sin que nos demos cuenta y que nos deja idiotas: pura cesura insistente, ruptura o diferencia entre dos dimensiones irreconciliables de tiempo. Más que la nueva o la antigua situación es el entre-dos

El acontecimiento de Deleuze es el momento en que se cruzan el pasado y el futuro, dejando siempre al presente como imposible lugar en que se encuentran, dado el devenir incesante del ser, diferentes intensidades, incompatibles con la negatividad, que cristalizan en un momento nuevo cuya duración es apenas un parpadeo. Ese destello es pura intensidad, parpadeo multidimensional e intensivo, pero ¿qué subyace bajo él?. Si realizásemos un corte en la superficie del plano, ¿encontraríamos el vacío bajo esa síntesis divergente? Más allá de las diferencias no hay nada, afirma Deleuze, pero esa nada no es el vacío sino el caos

Por supuesto que Deleuze no escapa a la falta de fundamento de su época, pero su desfundamiento es alegre y paradójico porque permite pasar algo por debajo del simulacro que es pura actualización superficial. Lo actual forma pareja indisoluble con lo virtual; se acoplan en movimiento de doble flujo que permite la circulación, según circuitos profundos o secundarios, de los modos del univoco ser.

Badiou afirma que el acontecimiento debe de ser una novedad radical que rompa con la situación y que sea garantía de que ha ocurrido algo más que el lugar vacío. El acontecimiento de Badiou es producción genérica a partir del cero, 
o múltiple de nada, pero el de Deleuze es la manifestación espacio-temporal de un momento, a la vez presente y pasado, del Ser en su eterno retorno. Nada hay vacío en el mundo deleuziano, los «átomos» erráticos son irreductibles, la materia es fuerza-tiempo que fluye, plegándose, replegándose, y desplegandose de nuevo, garantizando, así, la repetición ${ }^{4}$ siempre diferente del Uno.

$\mathrm{El}$ acontecimiento de Deleuze lo que manifiesta es la Memoria, mientras que el acontecimiento de Badiou es su interrupción. Para Badiou el acontecimiento es como una revolución, el final y la clausura de una época, para Deleuze el acontecimiento es tiempo, ruptura que permite pasar de una a otra dimensión e intensidad, pero se trata de un tiempo cuyo ser es intemporal. Badiou sostiene que el acontecimiento es verdad porque termina con la memoria y es despliegue de un comienzo. Deleuze no concibe un corte que sea verdadera ruptura sino una memoria que sube a la superficie en vía de actualización.

Y en este punto podríamos hacer intervenir el decir clínico de Deleuze para preguntarnos si se podría contemplar el objeto $<<a>>$ como cristalización de un tiempo-sujeto que sea la potencia de lo falso como simulacro, como cantidadcualidad de verdad actualizada cuando el Uno se fracciona en intensidades superficiales. Sin embargo, el objeto <<a>> es un semblante de ser, pero no es un simulacro: es subjetivación conseguida a golpes de asociación libre e interpretación. Aunque es un sujeto-objeto topológico, está producido por efectos de lenguaje, y si es el inconsciente el que habla, es decir, si el sujeto habla desde una estructura impersonal, no obstante, el inconsciente se juega desde la experiencia individual, desde la singularidad de la propia biografía.

¿Qué es el deseo para Deleuze? Es un afecto, lo que fuerza a pensar. No es falta ni espontaneidad. Se piensa. El deseo es local e individual, pero se confunde con las fuerzas, signos violentos que arrastran al sujeto a un devenir-otro. El deseo es más una sintesis pasiva que un impulso vacio que busca exteriorizarse. El deseo viene del Afuera y nace en un encuentro, después, una voluntad impersonal, un "empuje interior», conquistada en el encuentro, obedece. Se quiere el retorno.

4 Deleuze, G.: «Ce sont toujours les différences qui se ressemblent, qui sont analogues, opposés ou identiques: la différence est derrière toute chose, mais derrière la différence il n'y a rien". Différence et répétition, Paris, PUF, 1968, p.80. 
Si Deleuze admite algún tipo de sujeto es porque se asegura de que su sujeto esté impelido desde el afuera. Es desde el Abierto del Ser desde donde el sujeto-fuerza se despliega "empujado" por otras intensidades igualmente impersonales y cuyas relaciones son externas. El autómata al que Deleuze llama sujeto difiere radicalmente tanto de el sujeto del deseo inconsciente como de el militante de Badiou. Se parece más a lo que Foucault denominaba "Sí mismo». Deleuze salva Nietzsche por Foucault: el sujeto es creación porque es un plegamiento del afuera.

Badiou salva a Platón por Cantor y lo hace porque siguiendo la teoría de conjuntos, no contempla más que el múltiple sin fondo: el múltiple de múltiples impresentados, sin orden alguno, inconsistente. En ocasiones, algo de esta multiplicidad se somete a la operación de cuenta y se puede construir un subconjunto genérico, un sistema semiconsistente. Dejarse contar por uno es presentarse como consistente; dejarse contar, pero con al menos un punto de innombrable es presentarse como semiconsistente o genérico.

La verdad de Badiou viaja en un vehículo semi-inconsistente, es un subconjunto genérico. Lo genérico no es más que la puesta en obra, la semi-construcción, del exceso errante del ser que pone de manifiesto su carácter sustractivo.

Por ello, la verdad del sujeto militante no tendrá nada que ver con su propia biografía: no tiene pasado ni futuro personal, sólo fidelidad y coraje para dar fe de que el acontecimiento amoroso, político, artístico o científico ha tenido lugar.

Si hay algo en lo que Badiou insiste es en que el matema de un acontecimiento es el matema de un indecidible. El acontecimiento se dice siempre en futuro anterior porque el sujeto que fuerza con su intervención la verdad nacida del acontecimiento, lo que hace es apostar por lo que no se puede afirmar más que ilegítimamente: afirmar que un submúltiple pertenece o no pertenece a la situación. Tiene que apostar porque los elementos que el sujeto reúne son heterogéneos, no tienen nada en común, salvo pertenecer a la misma situación de la que son indiscernibles.

La verdad no puede decirse toda, pero el plus-de-goce es un medio decir perfectamente ubicado en la biografía del sujeto del inconsciente. Lo poco que el sujeto militante logra decir del acontecimiento es la respuesta a una llamada que 
lo sobrepasa porque excede los límites del lenguaje de la situación. El forzamiento que realiza el sujeto es una intervención en el lenguaje de la situación, para que los significantes adquieran una nueva significación, que no está dirigida al sujeto sino a todos, y que éste busca universalizar.

El punto clave de incompatibilidad de los sujetos ontológicos de Badiou y Deleuze está en las respectivas concepciones de la fuerza y de su punto de aplicación: La fuerza-tiempo de Deleuze es totalmente exterior al sujeto al que se aplica «sin permiso». El sujeto militante «elige» amar y guardar fidelidad al acontecimiento al que hace existir forzando con un nombre la «recolección» de los múltiples y dispersos elementos que la situación no contaba. Sujeto y acontecimiento, afirman tanto Badiou como Deleuze, se requieren mutuamente, no pueden ser uno sin otro, pero el autómata deleuziano es pura exterioridad.

El sujeto militante soporta el trayecto de una verdad que se inicia con una búsqueda, una serie de averiguaciones: preguntas dirigidas a unos y otros para saber el impacto que el acontecimiento ha producido en ellos. El sujeto tiene que encuestar a todo tipo de gentes con las que ensaya constatar que su anticipación ha sido certera. La encuesta sobre la veracidad del acontecimiento es una descripción del registro llevado a cabo sobre los resultados positivos y los negativos que permiten o no universalizar la hipótesis.

Si la verdad puede ser forzada, si se prueba su veracidad, afirma Badiou, es porque han sido descritas las modalidades de su torsión en espiral: la verdad como ultraser no puede ser más que universal, el plus-de-goce es particular, alcanzado mediante un procedimiento que requiere el uno por uno de la situación psicoanalítica.

Dado que el propio Badiou considera que la situación psicoanalítica es buena muestra de que todo acontecimiento está tejido con otros muchos acontecimientos, señalaremos que así es: el tiempo de duración de la cura no es lineal, es una torsión en espiral que supone un accidentado retorno de nuevos encuentros y nuevas nominaciones, ¿qué otra cosa podría ser el punto de capitón que frena la deriva metonímica?; pero la cura es una encuesta que más que encontrar no para de reencontrar. el psicoanálisis es una torsión en espiral que gira alrededor de unos pocos significantes amos, que no pueden ser cualesquiera, y que terminan reduciéndose a uno que adquiere una pre-determinada significación de goce. 
El sujeto de Deleuze es un tiempo-fuerza inicialmente inconsciente del eterno retorno. Y es que la cosmología de Deleuze ya no puede ser la del siglo XVII con un mecanicismo elemental donde el dinamismo era un mero equilibrio de ida y vuelta. Deleuze ya conoce el principio de incertidumbre procedente de la física cuántica y el espacio-tiempo como coordenadas equivalentes, aunque Deleuze contempla el tiempo como en si mismo multidimensional. La relatividad establece la correspondencia de planos y momentos de diversa intensidad que coexisten sin mantener relaciones causales. La repetición es siempre novedad porque la relación de fuerzas es siempre novedosa. Lo que se reencuentra es siempre una nueva disposición de las fuerzas. El psicoanálisis no encuentra lo que perdió, pero lo que coloca en su lugar, el objeto a, es una pre-determinación de goce, está tejido con el rastro de un significante.

En esa determinación reside la diferencia fundamental entre Lacan y Badiou: el acontecimiento de goce, que es el objeto «a», está predeterminado en su origen; se podrá o no llegar al final del análisis, pero el atravesamiento del fantasma no es otra cosa que la visualización de un objeto que estaba ya ejerciendo como destino del sujeto tachado del inconsciente. Su articulación en el fantasma lo que consigue es mitigar los efectos de tachadura que ya ejercía: el disco que se coloca orientando la banda de Möbius suaviza el fading del sujeto, cuya caída en el intervalo significante habrá quedado suavizada.

Lo nuevo en psicoanálisis hunde sus raíces en el origen del sujeto que sí es sustractivo; pero se trata de una sustracción de goce, no de la sustracción del ser en tanto que ser; no se trata del vacío que da nombre al ser, sino del agujero dejado por el recorte de goce que inflige la acción significante.

Lo nuevo de Deleuze es un nuevo disfraz, una actualización o simulacro de lo subyacente-Uno, divisible en infinitos modos que se disponen en otros tantos planos e intensidades relativas. Punto impensable en el pensamiento, el sujeto permite que lo múltiple pueda pensarse, íntegramente, como producción de simulacros, para que cada existencia sea sólo el perfil expresivo de la potente idea no-orgánica que contiene el mundo. 


\subsection{El sujeto tachado versus el sujeto militante}

Si consideramos al sujeto producido por el discurso psicoanalítico como una ficción, también podríamos denominarlo metáfora topológica, tendríamos que admitir que el sujeto tachado del inconsciente que es pura semblanza de ser.

Y aquí llegamos al punto culminante: ‘se pueden considerar equivalentes los términos semblante o semblanza con el de simulacro tal como lo considera Deleuze? Parece que no, que el grado de distancia que separa al psicoanálisis de la ontología deleuziana, es la noción de sujeto.

¿Puede hablarse de un sujeto deleuziano? Carente de toda "profundidad", sin subjetividad, ni posibilidad de acceder a un verdadero proceso de subjetivación, máquina pensante movida por el azar de las representaciones que lo invaden, es más un Artaud que un Descartes, aunque la definición rece: se piensa, o incluso, "piensa" (il pense), en el mismo sentido en que se dice que llueve (il pleut) y que hay viento.

El protagonismo del caso Artaud ha sido amplio en Francia, y más tarde ha emigrado a E.E.U.U. De Foucault a Derrida pasando por Deleuze, Artaud ha simbolizado la toma del sujeto por la omnipotente estructura, divinidad emergente que destituye al sujeto en mayor o menor grado. Lacan, y en general el psicoanálisis intentan resistirse, pero el ejemplo de Foucault se extiende a través de los estudios culturales sobre el género y las minorías, que ven en el etnocéntrico sujeto occidental el origen de todos sus males.

Lo que Deleuze denominó estilo indirecto libre se refiere, precisamente, a la indecidibildad respecto a la cuestión del ¿̨quién habla? Eso piensa a nuestras espaldas y nos vemos forzados y presionados por él. En su libro Foucault, Deleuze afirma: «Fuerza entre las fuerzas, el hombre no pliega las fuerzas que lo componen sin que el propio afuera se pliegue y abra un Sí mismo en el hombre" ${ }^{5}$. Habíamos ya afirmado que Deleuze salva a Nietzsche por Foucault, pero sería mejor expresarlo, siguiendo a Badiou ${ }^{6}:$ «Si leo por ejemplo «Fuerza entre las fuerzas, el

${ }^{5}$ Deleuze, G.: Foucault, Minuit, Paris, 1989 (Foucault, Barcelona, Paidos, 1987) p.121.

6 Badiou, A. (1997). Deleuze, "La clameur de l'Etren, Paris, Hachette, 1997, (El clamor del ser", Manantial, B. .Aires, 2002), p. 29. 
hombre no pliega las fuerzas que lo componen sin que el propio afuera se pliegue y abra un Sí mismo en el hombre», ¿es en verdad un enunciado de Foucault?, ¿o es simplemente una tesis de Deleuze, ya que se reconoce aquí su lectura de Netzsche? (...) se puede sostener indiferentemente que el enunciado en cuestión deviene de Foucault o que habrá sido de Deleuze"

La lengua no está toda a disposición del sujeto, pero, además, el objeto «a» impone al sujeto la marca de la pulsión de muerte; el sujeto escindido por el significante ha perdido el significante que respondería a la pregunta: ¿qué soy yo? Este significante crucial, el que da nombre y personaliza al sujeto, falta en el registro simbólico. Esta falta simbólica se dobla en lo Real con el objeto parcial perdido, que en el registro imaginario, se salva con la respuesta que el sujeto se da: si no hay respuesta en el Otro, el sujeto se aliena a lo que supone que este Otro le pide.

El sujeto se responde como puede, produciéndose un significado imaginario que llevará todo el análisis desentrañar y conducir al sinsentido. Así, podemos suponer respuestas del tipo: "el Otro quiere ser mirado", "el Otro quiere mirarme», de tal forma que el sujeto ignoraría que su destino es completar al Otro con la mirada que le falta. Así, el voyeur, ignoraría que su deseo está marcado por el axioma «el Otro quiere que le mire".

Sin embargo, el nuevo sentido que provendrá del desenmascaramiento de este falso ser imaginario, tampoco sutura el déficit ontológico. Aunque la semblanza de ser o plus-de-goce no advenga aleatoriamente; aunque no sea producto del azar sino del diseño y la técnica psicoanalítica, no es la recuperación del significante perdido en la urverdrängug. La sustracción del significante faltante es estructural, el plus-de-goce que resulta como resto de la operación psicoanalítica sólo vela la falta.

Lo que el matema del discurso psicoanalítico enuncia es el paso de una situación de sentido a otra distinta, mediación hecha del paso por la universal ausencia de sentido. Pero el nuevo sentido no puede ser cualquier sentido porque procede de una falta circunscrita. El fantasma no puede sino recuperar la huella del objeto perdido.

Otra cosa bien distinta es el sujeto de Badiou, que, desligado de todo objeto, no tiene otro objetivo que soportar el trayecto por el que una verdad advie- 
ne. Si tanto para Lacan como para Badiou, las nociones de verdad y de sujeto están orgánicamente entrelazadas, incluso, borromeamente enlazadas, hay que subrayar las diferencias en sus topologías respectivas ${ }^{7}$.

\section{a) La vacuola de goce versus la vacuola de ser}

Aunque tanto para Lacan como para Badiou la verdad sea lo que hace agujero en el saber, sus respectivos sujetos mantienen relaciones distintas con su verdad: el sujeto del inconsciente mantiene con su verdad una relación fraterna. El sujeto de Badiou mantiene una relación de fidelidad y militancia con la verdad, cuyo trayecto soporta con coraje.

La verdad de la que habla Badiou es hija del acontecimiento que se produce como un eclipse, y que exige un sujeto que apueste con coraje para que este eclipse de la verdad no se olvide. Sólo hay verdad si el sujeto conduce su trayecto, forzándola y anticipándola.

El sujeto del inconsciente mantiene una relación de oscilación entre gozar y pensar, mientras que el consciente simplemente trata de no saber sobre el goce que lo domina por muy prójimo suyo que éste sea. Tal como nos avisó Freud, el amor al prójimo, que Lacan considera como amor al objeto "a» en posición de extimidad, puede convertirse en su contrario porque los avatares de la pulsión incluyen su inversión. El amor fraterno es una posibilidad, pero el odio, la envidia, etc., están igualmente asegurados.

Mas el sujeto de la filosofía que Badiou construye no tiene una relación ambivalente con la verdad: el sujeto ${ }^{8}$ de Badiou no es consciencia ni inconsciencia de la

${ }^{7}$ Marqués Rodilla, Cristina.: El sujeto tachado, Madrid, Biblioteca Nueva, 2001; para conocer en profundidad la topología de Lacan consultar el capítulo VI.

8 "Il faut absolument abandonner toute définition du sujet qui supposerait qu'il connaît la vérité, ou qu'il lui est ajusté. Etant le moment local de la vérité, le sujet défaille à en soutenir l'adjonction globale. Toute vérité est transcendante au sujet, précisément parce que tout son être est d'en supporter l'effectuation. Le sujet n'est pas conscience ni inconscience du vraì. (Badiou, 1988: 435) El subrayado es mío.

Badiou es explícito respecto a un sujeto, el inconsciente, que no considera en cuanto tal; Badiou no subvierte sino que obvia la disyunción de los sujetos. El militante cree, está movido por el acon- 
verdad; se mantiene como fiel servidor de la verdad que le transciende, porque no la conoce, pero la olfatea y cree en ella, la sostiene con coraje; y trata de universalizarla, poniéndola a disposición de todos.

Es obvio que entre la verdad y el sentido Badiou lucha por la verdad, que en él es de carácter axiomático; Deleuze aplaude el sentido que no tiene por origen más que el sinsentido. En esto también es fiel a Foucault y a sus estudios sobre Roussel y Artaud. La verdad es "potencia de lo falso" ", concepto que Deleuze toma prestado de Nietzsche; capacidad de simulacro es la verdad deleuziana que el devenir actualiza incesantemente. El tiempo es la verdad porque es fuerza y signo

La falta de obra es inevitable. Una singularidad para Deleuze es la actualización, cualquiera de las infinitas, del ser unívoco. Podría decirse que no hay nada nuevo bajo el sol porque todo lo que pasa es inflexión del Uno, eterno retorno de lo Mismo. Pero también se puede decir lo contrario, que todo es constantemente nuevo porque el Uno vuelve en la perpetua creación de sus propios pliegues. La clave está en estos pliegues: son simulacros. El acontecimiento de Deleuze no es verdaderamente novedoso porque es el retorno del signo. Tampoco hay cortes sino devenir. La novedad se reduce al devenir de las fuerzas en planos de distinta intensidad; las diferencias son disposiciones nuevas de lo que vuelve: presentes coexistentes, velocidades relativas y yuxtaposición de planos, surgidos del único caos subyacente.

El semblante de ser del sujeto del inconsciente no es un simulacro aunque vele el sinsentido con un tejido de goce que da consistencia imaginaria al desvalido sujeto. La verdad nunca puede decirse toda, pero hay verdad aunque sólo pueda ser medio-dicha; El corte topológico o interpretación del analista separa al sujeto del deseo del Otro. Ese plus de ser, plus de goce, es una defensa.

tecimiento, que no conoce, lo que no significa que tenga un conocimiento inconsciente, sino que sigue los rastros, meras huellas, dejados por el acontecimiento.

9 Deleuze, G.: «El simulacro no es una copia degradada, encierra una potencia positiva que niega tanto el original como la copia, tanto el modelo como la reproducción». Logique du sens, Minuit, Paris, 1969 , p. 302; la traducción y el subrayado son míos. 
El acontecimiento de Badiou se genera en una situación, aunque la transciende originando una situación nueva: se trata de una cuenta excepcional ${ }^{10}$, que por un instante anula la repetición. Por tanto hay dos cuentas, la excepcional correspondiente al acontecimiento, y la de la situación; la operación de cuenta por uno es fundamental porque ser y ser-contado-por- uno son la misma cosa. Lo que no se presenta como contado por uno, simplemente no existe.

En la situación de partida hay una localización inconsistente, un exceso desordenado que si el azar lo permite, siendo como es de suyo indecidible, se contará a sí misma por una, dejándose subsumir parcialmente por los juegos de lenguaje. Lo que escapa a la lengua de la situación, y que reclama el forzamiento de un sujeto que lo avance con veracidad, es el nombre del acontecimiento.

El acontecimiento de la verdad ha surgido en situación, pero suplementándola con un supernumerario: un significante nuevo que trasforma la lengua de la situación agujereando la enciclopedia.

Lo importante, de cara a delimitar los sujetos de Badiou y Lacan, es ver cómo se produce el corte topológico. El psicoanalista realiza el acto analítico que es corte topológico que separa al sujeto articulándolo a su plus-de-goce. El resto de la operación de corte, o separación de analizante y analista, es el plus-de-goce. ¿Puede este plus-de-goce ser considerado una novedad, acontecimiento propicio resultado de la cura? Por supuesto que sí, pero eso no significa que sea un ultraser, un suplemento ontológico. Lacan se queda en la preontología. Lo que hay, el $Y$ a de l'un es la suplencia que hace semblanza de un ser irrecuperable.

Badiou recurre a la teoría de conjuntos para que, mediación hecha de las operaciones de cuenta y corte, esté permitido pasar de un exceso impresentado, incontable, a un plus de ser; este uno de más, que suplementa la situación, es ontológico: el plus de ser existe en y por el discurso que piensa los objetos que la matemática le propone.

${ }^{10}$ Marqués Rodilla, Cristina. : El acontecimiento del amor, Madrid, Biblioteca Nueva, 2006. Para conocer detalladamente las operaciones de cuenta, consultar el capítulo 3, esencialmente el epígrafe 3.2. 
El plus de Badiou no es un plus de goce, es un plus de ser, es un uno de más construido a partir del múltiple y que se cuenta a sí mismo por uno. Lacan construye el vacío de ser, lo circunscribe con un matema que expresa la carencia estructural. Badiou construye el ser del vacío, colocando un plus, un supernumerario que suplementa la situación. La diferencia es la que va desde una suplencia de ser a un suplemento.

Podemos considerar que la localización del múltiple inconsistente, exceso de cantidad desordenada e incontable, funciona, respecto a la situación, como vacuola, dado que este lugar donde se agita el exceso cuantitativo está en exclusión interna con la situación. ¿̨Cómo ${ }^{11}$ se pasa de esta exclusión interna a la separación respecto de la situación?

Aquí hay que subrayar que la vacuola ontológica contiene un ultraser, un número de más, que está en exclusión interna respecto a la situación en la que se obrará el corte. La situación psicoanalítica lo que tiene en exclusión interna es un plus de goce encerrado en una vacuola que contiene al representante de la sexualidad del sujeto tachado del inconsciente.

Lo que en ambos casos se exige es el corte topológico, que en la situación psicoanalítica, corre a cargo del psicoanalista, ¿pero quién, o mejor, qué realiza el corte que origina la novedad que Badiou considera un acontecimiento de ser?

1 La torsión en virtud de la cual el acontecimiento consigue, sin ruptura de plano, ser situación de los elementos de su localización y situación de sí mismo, puede ser representado por el objeto topológico de la banda de Möbius, es decir, por la cinta en la que se puede observar que posee, en todos los puntos de su contorno, dos caras distintas que tienen la particularidad confundirse a lo largo de toda la vuelta de su recorrido.

La utilidad de esta representación topológica del acontecimiento de Badiou reside en el hecho de que nos permite compararla con el sujeto de Lacan. El sujeto-banda de Lacan tiene que articularse con el resto, objeto «a", constituyendo un cross-cap. El resto de Badiou es el nombre que el sujeto "pone» al acontecimiento. Al autorrecortarse los elementos de la localización, el acontecimiento así producido es articulado por el sujeto con el nombre-resto de la operación; el nombre, ¿procede del acontecimiento o del sujeto?

La similitud es sólo aparente porque el psicoanalista realiza el corte, quedando el sujeto en relación de exclusión interna con su objeto. El acontecimiento se autorrecorta siguiendo su ley interna de funcionamiento y el sujeto se apodera de su nombre poniéndolo en circulación. Lacan no pasa el impasse, el corte separador articula, pero no rompe la alineación; sin embargo, el acontecimiento se autopertenece. 
El operador, que realiza el corte topológico en la situación, es matemático y procede de la teoría de Cantor. El acontecimiento es un múltiple excepcional que se añade a la situación, trazando el corte que lo separa de ella, y que consiste en la aplicación de una ley interna de funcionamiento. El corte topológico corre a cargo del operador matemático que realiza la cuenta de la autopresentación.

El corte que separa situación y acontecimiento es la operación de cuenta que reduce la multiplicidad inconsistente encerrada en la vacuola a un subconjunto excepcional que se autopertenece ${ }^{12}$, creándose así una nueva situación. Puede decirse que ese uno-de-más que es el acontecimiento ha podido añadirse a la situación porque ha sido realizada la operación de cuenta o corte topológico que convierte al acontecimiento en situación de sí mismo. Hasta aquí el acontecimiento, pero puede darse un paso más. El resto de esta operación de corte es la verdad: es la hija del acontecimiento.

\section{b) La operación deja un resto}

En este proceso, la intervención del sujeto es decisiva. La articulación del sujeto al acontecimiento es una doble implicación porque aunque el acontecimiento no exige el sujeto, de hecho, la existencia de éste es accidental, sin embargo, si éste no surge para dar fe de que la cuenta ha sido efectuada, o lo que es igual, para forzar un nombre y ponerlo en circulación, no hay advenimiento de la verdad.

La verdad es hija del acontecimiento, pero su nacimiento no depende de la acción del operador que Badiou llama sujeto. El acontecimiento se presenta a sí mismo, y para ello, el sujeto es indiferente. Pero el acontecimiento puede pasar desapercibido y sólo el sujeto al nombrarlo, al producir el resto de la operación de cuenta, lo convierte en una anticipación de la verdad en sí misma retroactiva. Resto de la operación de cuenta o hija del acontecimiento, lo mismo da, la verdad es un nombre supernumerario: un paso de más en la constitución del ser del vacío.

12 En El corto tratado de ontología transitoria, Badiou da cuenta de que el acontecimiento es un conjunto infundado porque es una situación que se sustrae a uno de los axiomas del múltiple: el axioma de fundación. 
La acción del sujeto, su operación de nombrar, de hacer aparecer un significante nuevo, o de darle una significación nueva a un significante de la situación, ¿en qué consiste?, ¿podría decirse que para Badiou, el sujeto es algo así como un partero de la verdad?

No, la metáfora de la comadrona surge de inmediato, pero ésta no responde al platonismo de Badiou.

La teoría de conjuntos convierte en simbólico el mítico embarazo de la verdad. La situación tiene en su seno, un proceso que, si acaba felizmente, dará lugar a una parte independiente de esa situación que Badiou llama acontecimiento o uno-de-más. Pero el sujeto no corta "el cordón umbilical» que unía al plus-deser con la situación en la que se ha gestado.

El proceso de gestación y el nacimiento de la verdad no incumben al sujeto, que no puede decidir sobre un embarazo y parto imprevisibles; son indecidibles; pero si el acontecimiento llega a producirse, es igualmente incierto que un sujeto soporte su advenimiento. Si hay acontecimiento, eso no indica que llegue a existir. El acontecimiento se da, ocurre, es decir, lo hay, pero sólo la intervención del sujeto lo hace existir.

El sujeto hace existir, donde lo hay, el acontecimiento, en sí mismo indecidible, porque fija su nombre, poniéndolo a trabajar en la situación.

¿Y si no aparece el efecto-sujeto que lo nombra y lo pone en circulación? Que sin la producción de ese resto, el eclipse en que el acontecimiento se agota habrá sido por nada, quedando olvidado. De ahí la importancia del azar, que puede dar al traste con el acontecimiento, la verdad y el sujeto que están orgánicamente articulados.

No hay efecto de verdad nada más que cuando hay un sujeto interviniente. Sólo si el sujeto se decide como el operador en cuya ausencia ninguna verdad puede ser visualizada, podemos afirmar que la verdad es hija del acontecimiento; acontecimiento que en nada depende del sujeto, pero que deja un resto.

Aunque el sujeto no haya influido para nada en la gestación ni en el nacimiento del acontecimiento que le precede, la verdad no advendría sin el forza- 
miento de un nombre, sin la militancia que sostiene el proceso de comprobaciones, necesario para averiguar si ese avance de la verdad, que hace el sujeto, puede sostenerse con veracidad.

La exigencia mutua de acontecimiento y sujeto que lo nombre, su mutua implicación no es exigida por la situación que preñada de una verdad, requiere un corte separador. El sujeto no es un operador ontológico, no procede de una necesidad ontológica, es aleatorio, aunque sea compatible con la ontología.

Pero hay algo más, el sujeto, subjetivamente escindido por el impacto que el carisma del acontecimiento ha causado en él, se adhiere libremente al acontecimiento al que nombra; la fidelidad del sujeto al azaroso proceso de su desenvolvimiento es una elección libremente decidida. El coraje del sujeto promoverá las encuestas, averiguaciones y confirmaciones que consoliden retroactivamente lo que inicialmente fue un avance realizado a expensas del sujeto militante.

Si Lacan se considera a sí mismo como el que realizó el paso del mito al logos del discurso psicoanalítico, ¿podríamos nosotros afirmar que esta misma operación es la que Badiou arriesga para el discurso filosófico? Si matemáticas y ontología son equivalentes, si la teoría de conjuntos proporciona los matemas que el discurso filosófico piensa, si la Idea platónica es construida siguiendo las pautas con las que Cantor construyó sus alephs, ¿qué otra cosa puede significar, sino que el platonismo contemporáneo es una formalización del antiguo mito de la Presencia?

\section{El Il y a del sujeto no significa que exista}

El sujeto hace existir el acontecimiento, hace la cuenta, nombra, pero, ¿existe él? La localización es una vacuola en exclusión interna respecto a la situación, que no es causa del acontecimiento, pero sí es su condición necesaria, sine qua non. $\mathrm{Y}$, ¿qué pasa entonces con el sujeto?

El sujeto hace existir el acontecimiento, lo que no quiere decir que sea el responsable de que lo haya; no es la comadrona que con su intervención ayuda a dar a luz a la verdad, efectuando el corte que hace que lo que era una pluralidad heterogénea de elementos de la situación, que ponía de manifiesto la inestabili- 
dad que subyace a toda cuenta por uno, advenga en la situación inicial aunque separándose totalmente de ella.

Dado que lo que subyace es el abigarramiento excesivo y desordenado de una localización, la cuenta situacional no sería suficiente porque el operador de la cuenta no es contado por ella. El corte del que surge el acontecimiento, separando la localización en exclusión interna respecto a la situación, es una cuenta extraordinaria porque el operador se cuenta a sí mismo: se autorrecorta.

La eficacia del operador matemático es tal que pasa el impasse de la estructura. El corte que efectúa el operador matemático-ontológico hace que la exclusión interna se convierta en acontecimiento que deja un resto: el nombre de la verdad, hija, o si se quiere, el resto del acontecimiento.

Hay sujeto, pero no existe porque él no es el héroe que rompe la barrera de la repetición, la novedad adviene por una cuenta que se rige por leyes internas de funcionamiento que Badiou toma de Cantor. El acontecimiento, como la verdad para Spinoza, es index sui.

El juego de la combinatoria conjuntista dicta la aparición indecidible e indiscernible del acontecimiento de Badiou y, si hay suerte, un sujeto lo nombra seducido por su verdad, que pregona a viento y marea. El sujeto-pliegue de Deleuze no pregona ninguna buena nueva sino que se pone al servicio de la potencia de lo falso como instrumento del eterno retorno de lo mismo. En ambos casos el acontecimiento obra y el sujeto obedece. La dicha de Badiou es el sujeto enamorado, sin duda pasivo bajo los hechizos de la verdad, pero fiel servidor de su dama. El sujeto de Deleuze no sabe nada del amor, ¿cómo podría amar una pobre máquina conducida por la fuerza-tiempo que deviene sin cesar? La verdad no es el acontecimiento sino el devenir, el paso del tiempo que con su fuerza actualiza las infinitas virtualidades del univoco ser.

Creo que en los tres casos puede hablarse del Il y a del sujeto. En ningún caso necesario, pero con mayor o menor grado de autonomía según vayamos de Lacan a Badiou para terminar con el autómata purificado de Deleuze al que resulta difícil llamar sujeto. Veamos qué pasa con el militante del acontecimiento y en qué medida sigue los pasos del sujeto del psicoanálisis. 
El sujeto es una figura del Il $y$ a, del "hay» de un procedimiento operativo; más la operatividad del sujeto no es necesaria: él no realiza la cuenta, ni es contado por ella: es aleatorio y pone en circulación un nombre; el sujeto fuerza la nominación, pero él mismo es accidental.

La capacidad de forzar un indecidible es tan importante que Badiou afirma en Conditions: «sí es posible dar una definición de sujeto (ésta sería): el que decide de un indecidible a partir de un indiscernible. $\mathrm{O}$, el que fuerza una veracidad según la suspensión de una verdad». (Badiou, 1988: 445)

Lo que es contado por la cuenta es su operador ontológico: el acontecimiento. El sujeto le da nombre y lo hace circular, pero él no es nombrado. Ser contado por la cuenta es existir, tener nombre propio es existir, pero el sujeto es un indiscernible.

Un indiscernible es una pluralidad de indiferentes entre los cuales es imposible distinguir. Del sujeto podrían, se deberían predicar propiedades, pero es indiferente a ellas. Es genérico e innombrable aunque realiza una labor inestimable de coraje y fidelidad que impide que el eclipse que es el acontecimiento se olvide.

$\mathrm{El}$ acontecimiento se autopertenece, la ontología no exige al sujeto aunque éste sea compatible con ella: el acontecimiento es un múltiple excepcional que se presenta a sí mismo. Pero su novedad y excepcionalidad tienden hacía «abajo", a la desaparición. La verdad no es una epifanía, no es un estallido, o si se le quiere llamar estallido hay que añadir, como lo hace Badiou: no-existente. Hay estallido, sin embargo es no-existente. La verdad es un retraimiento hacía el vacío que bordea.

$\mathrm{El}$ acontecimiento es un intervalo y uno de sus bordes es el vacío, el otro es el nombre que pone el sujeto; su intervención es la que, al nombrarlo, lo hace existir; además, permite su inscripción en el discurso, aunque el encargado de que lo haya, el que le da el ser, es el operador ontológico-matemático.

Badiou insiste en que nada se puede predicar del sujeto, que no es necesario aunque sea compatible con la ontología. Su intervención fija el nombre del acontecimiento, perseverando en la cadena de averiguaciones, con la certeza anticipada de que un día la verdad habrá sido. 
La importancia del sujeto, asunto nada baladí, oscila según lo consideremos como lo que funda la posibilidad de la intervención que da existencia al acontecimiento o que, simplemente, sea considerado como el que se apodera del nombre para hacerlo trabajar en la situación.

La diferencia aquí apuntada no concierne el objetivo de este estudio, pero nos parece de la máxima importancia; sólo añadiremos que si el sujeto no funda la posibilidad de su intervención, entonces, el acontecimiento se autonombra $^{13}$ y el sujeto se limita a tomar y pasar el testigo de lo que puede incluso ser una fábula.

Lo que sí es necesario, lo que es condición sine qua non es la localización de un múltiple inestable e inconsistente, que es el lugar de la situación en que se gestará el acontecimiento de la verdad. La verdad del acontecimiento requiere su localización en la situación, pero no la existencia del sujeto; el corte es efectuado en la localización y consiste en una operación de autopresentación.

Realizada esta cuenta-corte, el eclipse se ha producido: el sujeto se apodera del nombre y lo hace circular; pero el sujeto es raro y podría no ocurrir; es accidental, aunque no es contrario al proceso que podría ocurrir sin él. El acontecimiento se presenta a sí mismo como otro de la situación, sin que esté garantizada la fidelidad de un sujeto que asegure el resto-verdad de la operación.

\section{a) La verdad es hija del acontecimiento}

La interconexión entre el acontecimiento, la verdad y el sujeto constituye un nudo borromeo. El nombre del acontecimiento es el resto que ocupa el vacío central del nudo.

El acontecimiento surge en situación, en una localización indiscernible en la cual se efectuará el corte topológico, que es la cuenta por uno que el acontecimiento realiza de sí mismo. Puede, pues, afirmarse que el matema de un acontecimiento expresa discerniblemente un indiscernible.

${ }^{13}$ Si un múltiple, el acontecimiento, es el «nombre dont il est le nom», en (Badiou, 1990: 120), parece que el sujeto se apodera, hace bandera, de la autonomización del acontecimiento, para salvarlo del olvido. El nombre es así, un resto dejado por el acontecimiento en su presentación. 
Queda explicitar el procedimiento, el proceso subjetivo, que hará posible decir un día el "habrá sido" de la verdad en sí misma genérica e incompleta. La creencia del sujeto en que algo ha ocurrido, que es un suceso novedoso y memorable, inicia la construcción de una verdad que, en ningún caso, puede ser coextensiva al mortal militante que la defiende, en ocasiones hasta con su vida.

$\mathrm{El}$ acontecimiento ha dejado un resto, que hay que constituir como verdad hija del acontecimiento. El sujeto pone a trabajar el nombre del acontecimiento en la situación para poder elaborar la verdad del acontecimiento.

El sujeto tiene que establecer la conexión entre el nombre del acontecimiento y los múltiples de la situación; la situación de la que ha emergido el acontecimiento cuenta por uno una multiplicidad de múltiples; el acontecimiento no es más que uno de esos múltiples indiscernibles por los que el sujeto apuesta; el sujeto apuesta por algo indecidible porque cree que el acontecimiento ha tenido lugar realmente.

La localización del acontecimiento bordea el vacío, pero también bordea el nombre.

La tarea del sujeto reside en poner en conexión ese nombre con otros de la situación para poder establecer si la conexión es positiva, negativa o indecidible.

Cuando la conexión es indecidible, el sujeto está atrapado. En ese caso, el sujeto tiene que proseguir su tarea hasta que las conexiones afirmativas y las negativas no estén equilibradas; sólo el coraje y la búsqueda de nuevos casos permitirán, si la suerte se muestra propicia, inclinar la balanza hacia el lado de las conexiones afirmativas.

Establecer la conexión entre el nombre y la situación es inscribir el nombre en la situación. Podemos, pues, afirmar que el nombre es el tenant-lieu (sostén) de lo ocurrido; lo sucedido es el acontecimiento, uno de cuyos bordes es el vacío, lo que nos permite decir que ha tenido lugar al borde del hors-lieu (fuera de lugar). Al sujeto le queda la tarea de afirmar que ha tenido lugar algo más que el lugar, lo que puede decirse: el lugarteniente (lieutenant) del nombre, y del acontecimiento, es el sujeto; militante de un suceso que puede, en ocasiones, no ser más que una fábula, y que, además, no conoce, aunque lo afirme. 
Pero hay algo más, el sujeto, lugarteniente del acontecimiento, se apoya en el nombre-sostén (tenant-lieu) para hacer advenir la verdad-lugar (lieu-tenant) del acontecimiento. El sujeto hace insistir lo que ek-siste, originando lo que soporta la consistencia de una situación.

El procedimiento de verdad consiste, pues, en hacer insistir lo que ek-siste: el sujeto pone a disposición de todos el nombre del acontecimiento, iniciando una investigación que hace una recensión de los múltiples de la situación que se avienen positivamente al acontecimiento, o mejor, a su nombre. La comprobación, caso por caso, de la conexión entre el nombre y los múltiples es fundamental porque no hay otro modo de averiguar si los múltiples se sienten concernidos por el acontecimiento.

\section{b) La verdad es un proceso subjetivo}

La encuesta militante que realiza el sujeto es radical. Lo que hace el sujeto, que no es un obrero, ni un funcionario, ni un artista, dado que ningún trazo predicativo acompaña al sujeto, es pensar la situación según el acontecimiento. Lo que busca saber es cómo las gentes reaccionan al nombre del acontecimiento.

El sujeto no dispone a priori de ningún dato que le permita saber si un término está o no positivamente correlacionado con la situación; su trayectoria se decide al azar; en esta decisión aleatoria reside la libertad del sujeto.

El sujeto hace circular el nombre del acontecimiento porque va preguntando a todo el mundo, guiándose únicamente por el azar de los encuentros; así tiene que preguntar, por el triunfo de la Revolución o por la muerte de Cristo, a gentes de todas las edades, culturas y profesiones, así como de todas las condiciones sociales.

El caso de San Pablo, que Badiou ha analizado a fondo, pone de manifiesto la eficacia militante en la consolidación de una verdad: la hija del acontecimiento "muerte de Cristo". La fidelidad y coraje de San Pablo, fundador de una Iglesia, permitió la inscripción de una comunidad universal de seguidores y creyentes, los cristianos. 
Un acontecimiento es una fuente de verdad, pero ésta exige una anticipación realizada por la intervención militante, que de ese modo, la va actualizando; la actualiza en el transcurso del proceso subjetivo que genera y cristaliza una verdad. El acontecimiento abre una posibilidad que el sujeto realiza en situación. Así, poco importa que la muerte de Cristo sea o no sea un hecho histórico, lo fundamental es que la posibilidad cristalizó en una Iglesia depositaria de la verdad cristiana.

\section{La verdad elige el autómata purificado}

En el Antiedipo (1972), Deleuze denunciaba que el psicoanálisis era el último reducto de los curas que seguían ejerciendo su poder a través de la culpa que ahora ya no era inoculada por la Iglesia sino por la familia. Deleuze denunciaba la falta de visión sociopolítica de un psicoanálisis anclado en la importancia de la familia como agente trasmisor, dado que seguía considerando un sujeto dotado de intimidad al más puro estilo cartesiano.

Deleuze explica que el gran error de Descartes consistió en aislar como certeza absoluta lo que no era más que una concreción momentánea en el devenir del omnímodo Uno. Lacan y los demás psicoanalistas seguían reos de una visión periclitada de sujeto.

Sabemos que Lacan hizo al menos cinco interpretaciones del cogito cartesiano. En este artículo nos hemos referido a la que reza: "o pienso o existo". Disyunción exclusiva que enuncia que el sujeto del inconsciente oscila, pestanea, entre pensar y gozar. Cuando goza no quiere, ni puede, hacerse cargo del mensaje inconsciente $y$, cuando piensa, desea saber sobre su inconsciente, construirlo.

Lacan realiza una lectura subversiva de Descartes, pero no elimina el cogito sino que lo transforma, lo hace funcionar en "otro escenario». Si el cogito consciente es imaginario, según Lacan, el cogito inconsciente es simbólico. Pero más allá del cambio de escenario, el yo sigue siendo un lugar vacío que necesita ser "rellenado"; aunque ya no se trata de representaciones, sino de la estructura. El sujeto pierde autonomía pero sigue existiendo mediante un tejido de goce, el objeto a, que construye mientras piensa tumbado en el diván. 


\subsection{Producciones deseantes}

El inconsciente es para Deleuze una antigualla que no tiene en cuenta las fuerzas, siempre externas, que son las estructuras económicas y sociopolíticas. La deriva psicótica de la sociedad de los años setenta se debía, según Deleuze, a condiciones que nada tenían que ver con un sujeto educado en una familia pequeño burguesa que le seguía dirigiendo a través del Nombre del padre. Según Deleuze de lo que se trataba era de seguir las bellas palabras de Foucault y asegurar con él que. uel familiarismo inherente al psicoanálisis corona la psiquiatría clásica más bien que la destruye ${ }^{14}$.

Para Deleuze-Foucault está claro que el psicoanálisis no es capaz de hacer autocrítica. Si la hiciera descubriría. «bajo la proyección familiar la naturaleza de las catexis sociales del inconsciente (...) llevar(ía) el simulacro hasta el punto en que deja de ser imagen de imagen para encontrar las figuras abstractas, los flujos-esquizias, que entraña ocultándolos. Sustituir el sujeto privado de la castración (...) que remite tan sólo a los dos órdenes de imágenes personales, por los agentes colectivos que remiten por su cuenta a disposiciones maquinicas. Volver a verter el teatro de la representación en el orden de la producción deseante: toda la tarea del esquizoanálisis» ${ }^{15}$.

Así es que poco tiene que ver el decir clínico de Deleuze, que diagnostica una esquizofrenia social ligada al régimen de producción capitalista, con la teoría freudiana que no quiere admitir que habiendo sido previamente un hijo, es él, el padre-Freud, el que con su paranoia edipiza al hijo. La culpabilidad es antes una proyección paterna que una interiorización del hijo. De todas formas si fuéramos obedientes a Deleuze no deberíamos preguntarnos quién fue primero si el padre o el hijo porque esto nos mantiene en el familiarismo. Lo primero es la catexis del campo social en el que la familia, como subconjunto, está sumergida. La sociedad es psicótica porque el sujeto está atravesado por el afuera. Es lo Abierto lo que crea y dirige al sujeto, el resto son pliegues.

${ }^{14}$ Deleuze, G.y Guattari, F.: Capitalismo et schizophénie, t 1. L'Anti-Oedipe, Paris, Minuit, 1972 (El antiedipo, capitalismo y esquizofrenia, Barral Editores, Barcelona, 1973), p.279.

15 Ibid., p. 279; la cursiva es mía. 
Según el decir heideggeriano podríamos afirmar que el salto, gravísimo, se ha efectuado. Si el sujeto habitaba en la casa del lenguaje, lo que éste le producía, según el psicoanálisis freudolacaniano, eran malentendidos neuróticos; sin embargo, el decir deleuziano amplia el campo de la psicosis que nos concierne a todos: el lenguaje se ha apoderado de nosotros; somos habitados por el lenguaje, que nos atraviesa y nos mata; nos impide nacer, como al pobre Artaud.

A partir de aquí la mediación de Lacan no da más de sí. Deleuze no contempla ningún vacío, tampoco el del sujeto. Pero por el camino también hemos perdido a Badiou que se sirve del psicoanálisis para que el sujeto sea sexuado, para que el militante sea un sujeto enamorado, pero gozante. No hay amor donde éste no está anclado en el goce sexual. Nada más hay en el militante de Badiou que tenga que ver con el sujeto de Lacan. La diferencia radica en la ubicación del vacío: vacío del ser para Lacan, ser del vacío para Badiou. El sujeto de Badiou es sin objeto y el de Lacan es un objeto, el objeto a minúscula.

Lo que está claro para Deleuze es que no podemos seguir pensando así, no es que no se quiera es que no se puede: No es "nuestro" problema, y un problema es el "nuestro" porque es nuevo y porque la renovación de las condiciones históricas emite signos inéditos. Ya no podemos seguir, en esto da la razón a Heidegger, hablando de una metafísica del sujeto. El «sujeto» de Deleuze es un autómata purificado, lo que excluye toda interioridad, tanto referida a símisma (reflexividad) como a sus objetos, dados como heterogéneos con respecto a la interioridad (negatividad). No se puede obviar su profundo antihegelianismo.

Sólo se puede hablar de sujeto si se acepta que es una inflexión superficial, un simulacro. La oposición entre el afuera y el adentro significa que un plegamiento del afuera crea la interioridad de un si mismo. Pero esta interioridad es un resultado, no es constituyente de sí misma sino constituida. Es constituida porque el acto de plegar (o de desplegar) es un acto del Ser. La construcción del si mismo es un pliegue del Ser. El sí mismo es construido al plegarse o desplegarse el Ser en su incesante devenir.

Pero lo fundamental de este «sujeto-pensamiento" es su total falta de intencionalidad. Su aposición frontal a la fenomenología está contrarrestada por la fuerza de lo Abierto que impele el pensamiento. Deleuze reitera hasta la sacie- 
dad que el pensar es un forzamiento, que no hay espontaneidad ni intencionalidad, sino forzamiento: se piensa.

El autómata está separado del mundo exterior pero hay un afuera más profundo que viene a animarlo. La intuición, el pensamiento, empieza animado desde el afuera, ¿y cómo lo hace? Anima porque es fuerza-tiempo, es fuerza-devenir; el afuera impersonal está poblado de fuerzas que componen las formas. El pensamiento autómata es puesto en movimiento por la fuerza, el pensamiento es animación forzada del afuera que sólo se manifiesta como imposición de una fuer$z a$ en devenir. El afuera es una relación de fuerzas en constante trasformación.

El sujeto como pliegue del afuera supone la creación de un bolsillo interior y este pliegue es, finalmente, "subjetivo" porque es un archivo que guarda la memoria. Un sujeto sería «memoria del afuera». En su libro sobre Foucault, Deleuze afirma: «el tiempo como sujeto, o más bien como subjetivación, se llama memoria»(Deleuze, 1986: 115). Y esto es así porque ser sujeto es: "pensar el afuera como tiempo, bajo la condición del pliegue» (Ibid).

Si dado el automatismo del sujeto deleuziano tenemos la tentación de decir que éste ha sido eliminado, antes de caer en ella deberíamos tener en cuenta que su ambigüedad procede de que el sentir del sujeto es «sentir que yo devengo otro", lo que indica el descentramiento del sujeto que no es causa sino efecto de sus pensamientos: el sujeto es concluido por los estados por los que va pasando. El sujeto no es origen de pensamientos ni de deseos, es un residuo. Cuando se da cuenta ya está en otra cosa, así es que el sujeto dice: "yo era». O aún más gráficamente: ¡era eso, entonces!, ¡entonces, soy yo!

\subsection{Un residuo que no es un resto}

¿Qué el sujeto sea un residuo lo asemeja al sujeto del inconsciente? Sólo en los orígenes del pensamiento, cuando el sujeto es tomado, forzado, por el pensar se puede decir que el pensamiento es inconsciente porque no tiene la forma de una conciencia: no es un escenario donde se representa un drama, parece más bien una fábrica cuyas máquinas producen pensamientos. Y el acto de pensar no es inconsciente, se engendra inconscientemente. El sujeto es forzado por el afuera y no domina el comienzo del pensamiento, que se da en un campo de fuerzas que 
Deleuze llama inconsciente; hacia la mitad el sujeto fabrica conceptos $y$, a toro pasado se da cuenta de cuál ha sido su papel en el proceso de animación maquínica.. No hay identidad y la identificación comienza siempre demasiado tarde, a posteriori.

Vemos la diferencia con el sujeto lacaniano que se aliena en sus orígenes al deseo del Otro y se busca, inevitablemente, una respuesta imaginaria para dicho deseo. El sujeto «decide» que el Otro quiere ser mirado, obedecido, violentado, etc., porque busca desesperadamente darse nombre, identidad. Pero Deleuze no quiere representaciones, rechaza un sujeto nutrido con fantasmas familiares y busca un sujeto cuya coherencia secreta excluye la del yo.

Una máquina que sea el espejo de las tensiones entre los flujos de fuerzasdeseos de distinta intensidad. El Edipo no estructura el campo afectivo que originalmente no es más que un campo de fuerzas, al que se puede llamar inconsciente porque sólo más tarde hay una interiorización de lo que estas fuerzas significan. Esta interiorización afectiva es considerada por Deleuze como la metáfora de todas las interiorizaciones a las que el sujeto será sometido por la exterioridad de las relaciones.

Para Deleuze un sujeto es un hombre sin nombre, sin familia, sin cualidades, un sujeto que deviene, que no cesa de devenir, que puede afirmar "yo soy" en tanto que deviene otro y se sorprende de lo sucedido. El autómata de Deleuze se descubre a sí mismo in fraganti cuando al delito cometido lo único que puede ponérsele es pecho: anda, pero si resulta que jese era yo!

Badiou define un militante que vive un momento histórico concreto, pero la Verdad es intemporal y él la reconoce y la hace existir para siempre, o se equivoca para siempre. Es un amante que lucha por una causa aunque no la entienda. Es un activista que busca constituir una comunidad, de ahí que el sujeto de Badiou esté feminizado. Badiou afirma que la mujer no puede vivir sin amor porque antológicamente quedaría dañada por su falta.

Y si a primera vista pareciera que los sujetos de Badiou y Deleuze son plenamente divergentes, dado que son en virtud de dos modelos de acontecimiento bien distintos, cuando se consideran más despacio hay en el par azar/elección algunas resonancias. 
Esa vocación del sujeto de Badiou por el acontecimiento, su deseo de fidelidad, y su amor por la universalización de la verdad acontecida, parecen un destino. El sujeto puede no aparecer; pero si hay sujeto su entrega al acontecimiento, ¿no podría considerarse como un implícito "hágase en mím el pensamiento?

Las resonancias respecto a la elección son claras pues se trata de dejarse elegir. El sujeto no es necesario y puede faltar o haberlo, pero el militante de Badiou parece fascinado por el clamor del acontecimiento que sólo él, apóstol de su verdad, escucha inicialmente. El autómata de Deleuze es tomado rehén de la fuerza-Uno, pudiendo, eso si, no resistirse a pensar lo que el afuera le dicta.

Badiou parece querer convencer con sus argumentos matemáticos y Deleuze seducir con su física ficción, pero quizás se trate de un juego de espejos: seducir convenciendo versus un convencer seduciendo. 